\title{
Rare surgically correctable form of primary aldosteronism
}

INSERM

\section{Source}

INSERM. (1999). Orphanet: an online rare disease and orphan drug data base. Rare surgically correctable form of primary aldosteronism. ORPHA:231637

Surgically correctable forms of primary aldosteronism (also known as primary hyperaldosteronism; see this term) are characterized by unilateral aldosterone hypersecretion and renin suppression, associated with varying degrees of hypertension and hypokalemia. 